\title{
REPEATABILITY OF FORCE PRODUCTION AS A MEASURE OF KINAESTHETIC SENSE IN SEAGOING SAILORS AND RECREATIONAL SAILORS
}

original paper

( ) University School of Physical Education in Wroclaw

DOI: https://doi.org/10.5114/hm.2019.83219

\section{RYSZARD BLACHA ${ }^{1}$, KRYSTYNA ZATON ${ }^{1}$, PIOTR PIWOWARCZYK ${ }^{1}$, AGNIESZKA JASTRZEBSKA ${ }^{2}$, STEFAN SZCZEPAN ${ }^{1}$}

${ }^{1}$ Department of Swimming, University School of Physical Education in Wroclaw, Wroclaw, Poland

${ }^{2}$ Department of Physiology and Biochemistry, University School of Physical Education in Wroclaw, Wroclaw, Poland

\begin{abstract}
Purpose. The unstable environment and the swaying, rolling, and pitching motions experienced when offshore sailing may disturb motor function and negatively affect personal safety. The aim of the study was to investigate changes in lower limb kinaesthetic sense in sailors after spending time onboard a seagoing vessel.

Methods. The study involved 39 subjects, of which 13 were professional sailors (PS) (age $\bar{x}=22.56 \pm 0.83$ years), 13 were recreational sailors (RS) (age $\bar{x}=31.50 \pm 7.35$ years), and 13 served as a non-sailor group (NS) (age $\bar{x}=21.02 \pm 0.82$ years) with no sailing experience. PS attended a 1-month on-sea training course, RS attended a 1-month seagoing cruise, and NS did not sail or participate in any congruent activity during the study duration. Kinaesthetic sense was quantified before and after the interventions by a force-matching task in which the force production accuracy (FPA) was measured on a customdesigned kinesthesiometer. The participants performed 5 right and left single-leg extensions at a force perceived to be equal to $10 \mathrm{~kg}(98 \mathrm{~N})$.
\end{abstract}

Results. Right and left limb FPA increased in PS by $0.70 \%$ and $79.12 \%$ and in RS by $18.97 \%$ and $20.26 \%$, respectively. In NS, right and left FPA decreased by $6.97 \%$ and $1.42 \%$, respectively. Only the difference for left limb FPA in the PS group achieved statistical significance $(p=0.0006)$.

Conclusions. A 1-month sailing intervention reduced lower limb kinaesthesia as measured by the accuracy of reproducing a pre-specified force magnitude.

Key words: sailors, force magnitude production, kinaesthesia

\section{Introduction}

The popularity of sailing has increased over recent years in both the recreational and racing domains. Improved infrastructure, technological aids, and simplified licensure have made this an accessible activity for many individuals [1]. Sailing in the $21^{\text {st }}$ century is almost always performed for recreation or sport on various classes of sailing vessels. As a leisure activity, it involves day-sailing or cruising trips for adventure, pleasure, or health reasons [2]. As a form of competition, sailing is characterized by highly varied duration and a focus on high performance combined with greater risk [3]. Within these two general pro- files, sailing is divided into numerous categories of purpose that interweave a broad range of utilitarian, social, and personal values, making it a very versatile activity.

As sailing crafts operate on open water, they are subject to numerous weather, climatic, and environmental conditions. The natural phenomena that impact the physics of sailing, such as wind strength and direction, wave height, tides, and currents, can change dynamically in a short time, requiring sailors to react in a wide variety of ways [4]. Environmental conditions also include such factors as the characteristics of the body of water and the presence of other watercrafts [5]. With regard to controlling the vessel,

Correspondence address: Stefan Szczepan, Department of Swimming, University School of Physical Education in Wroclaw, al. I.J. Paderewskiego 35, 51-612 Wroclaw, Poland, e-mail: stefan.szczepan@awf.wroc.pl

Received: October 3, 2018

Accepted for publication: February 19, 2019

Citation: Blacha R, Zaton K, Piwowarczyk P, Jastrzebska A, Szczepan S. Repeatability of force production as a measure of kinaesthetic sense in seagoing sailors and recreational sailors. Hum Mov. 2019;20(2):57-63; doi: https://doi.org/10.5114/ hm.2019.83219. 
R. Blacha et al., Kinaesthetic sense in seagoing and recreational sailors

the most critical actions are those that modify the point of sail and induce course changes. Hence, an important safety aspect of sailing is the perception of external stimuli and rapid response by modifying the speed and direction of the vessel. Quick decision making with appropriate and continual control inputs in effect determines sailing performance [6].

Excluding the external characteristics of the environment, hull and sail design, sailing tactics or sailor skill and experience, additional factors that influence performance are the physiological and physical abilities of the sailor [7]. Critical are the biomotor abilities that comprise the fitness and coordination domains [8]. These abilities directly influence the efficacy of many sailing tasks and include strength (for the control of running rigging or rudder manipulation), endurance (during extended activity that is primarily isometric and of variable intensity), spatial orientation (assessment of changes in body position, as well as vessel and sail orientation), reaction time (to determine the temporal properties of an action in dynamically changing conditions), balance (for maintaining a stable position of the body on the unstable and swaying surface of the deck), and kinaesthesia or kinaesthetic differentiation (sensing the speed, direction, and amplitude of body movements and determining the most appropriate motor response) [9]. The last ability aids in defining the strength, temporal, and spatial components of a movement [10] and is also responsible for mechanical efficiency and movement precision [11]. Enhanced kinaesthetic sense can improve sensory processing and the integration of feedback on muscle tension (strength component), muscle velocity (temporal component), and joint angulation (spatial component) [12].

The aquatic environment of sailing, subject to a wide range of weather and climatic conditions, the inherent characteristics of inland or ocean-going sailing, and the design of sailing vessels can each disturb the functioning of various physiological mechanisms [13]. Most prominent for individuals who spend time on a craft on water is the onset of motion sickness (kinetosis), manifested by headache, drowsiness, nausea, impaired movement, and confusion [14], all of which can significantly limit onboard safety. Kinetosis is understood as the incongruence between peripheral neural information such as visual or auditory information (via exteroceptors) and vestibular and body position information (via proprioceptors) with previously stored dryland motor schemas [15]. If not prevented or treated, the disturbance can last until the sensory conflict is resolved by the creation of new motor pro- grams [16]. This includes conflicting information originating from multiple sensory pathways comprising the vestibular apparatus (providing a sense of balance and spatial orientation), muscle spindles (detecting changes in muscle length and velocity), and Golgi tendon organs (sensing change in muscle tension) [17] and can negatively affect a wide range of motor functions [18].

The majority of exercise science research on sailing has investigated the physiological responses to specific sailing manoeuvers [19], energy expenditure in sailing [20], and the role of coordination ability, such as eye-steering, in the sailing strategy [21]. Others have focused on the yachting technique and, for example, the use of computer simulations for training and assessment purposes [22]. However, no studies to date have addressed changes in the level of kinaesthetic sense among sailors, particularly after spending time on the water. Therefore, the aim of the present study was to evaluate these dynamics in the lower limbs, which may be relevant to both sailing performance and safety. It was hypothesized that the time spent onboard a seagoing vessel would decrease the level of lower limb kinaesthetic differentiation.

\section{Material and methods}

\section{Participants}

Overall, 39 physically active and healthy males were recruited; 13 were professional sailors (age: $22.56 \pm$ 0.83 years, body height: $179.39 \pm 4.02 \mathrm{~cm}$, body mass: $74.39 \pm 8.28 \mathrm{~kg}$ ), 13 were recreational sailors (age: $31.50 \pm 7.35$ years, body height: $182.21 \pm 5.17 \mathrm{~cm}$, body mass: $82.07 \pm 7.89 \mathrm{~kg}$ ), and 13 were individuals with no history of sailing, who constituted a group of non-sailors (age: $21.02 \pm 0.82$ years, body height: $178.25 \pm 5.41 \mathrm{~cm}$, body mass: $72.13 \pm 8.45 \mathrm{~kg}$ ). The professional sailors were second year students of a higher maritime college, educated towards the profession of a sailor. During their education, they had spent about 90 days a year on ships performing basic seaman's duties. The recreational sailors sailed as a hobby during their free time, with an average of 14 days of sailing a year. During the study, the group of professional sailors participated in a 1-month on-sea training course, and the recreational sailors attended a 1-month seagoing cruise. These activities took place in similar technical and environmental conditions. The units were ships with sails. The hull caused similar wobble in all units. The subjects sailed at sea between of June and July, in similar atmospheric conditions. During 
the cruise, each of the subjects was part of the crew who served the unit. During the 4-hour daily shift, the participants performed basic activities, which included steering of unit, handling of sails, climbing on the mast, deck washing, rope pulling. The non-sailors did not sail or participate in any congruent activity during this time. All subjects were right-handed and achieved full psychomotor development. No statistically significant between-group differences were observed for age, body height, or body mass $(p>0.05)$. However, the between-group difference test for the pre-test indicated differences in the ability of kinaesthetic sense, which causes caution in inference. The participants were informed that they could withdraw at any time. They were instructed to maintain their normal diet and refrain from alcohol and caffeine for 24 hours before testing [23].

\section{Testing apparatus}

Kinaesthetic differentiation was quantified by a lowerlimb force matching assessment in which the accuracy of reproducing a pre-specified force magnitude in static conditions was measured. Force matching tasks involving maximal or sub-maximal force production and utilizing various measurement methodologies have previously been used to quantify the level of kin-

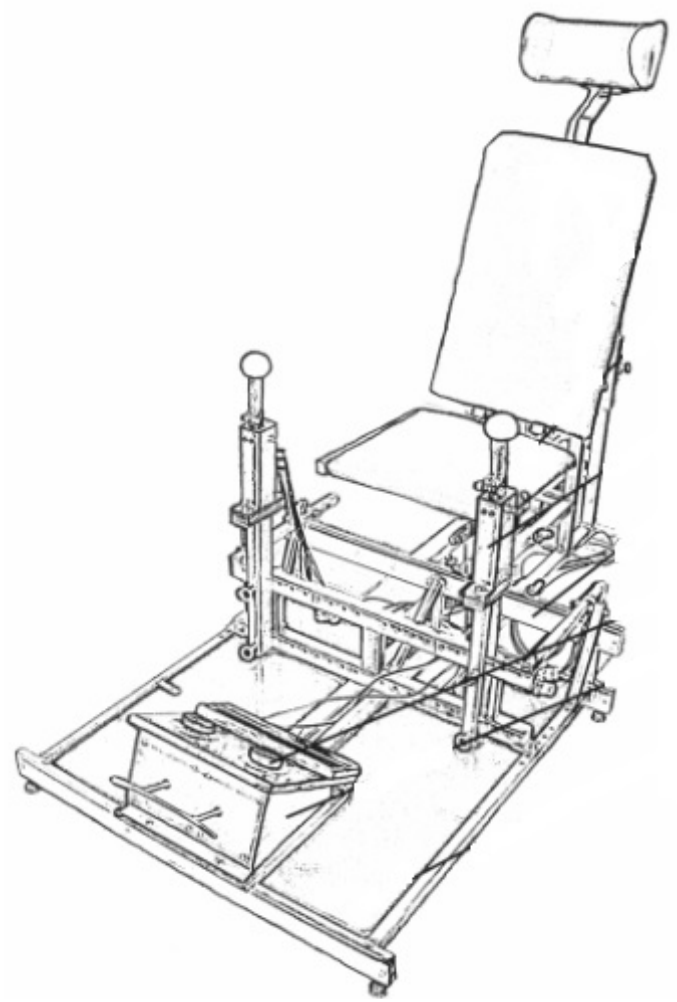

Figure 1. The kinesthesiometer for measuring the repeated isometric force of upper and lower limbs [28] aesthesia in functional movement assessments [12, $24,25]$. For the purposes of this study, a custom-designed kinesthesiometer (Polish patent \#PL213505B1), developed and validated by Błacha [24], was selected (Figure 1). It uses an adjustable exercise chair modified to include 2 pedals and 2 hand levers connected to force transducers [26]. Lower limb testing was performed with both feet resting on the pedals of the kinesthesiometer. The participant maintained their arms crossed over the chest in order to eliminate the effects of additional skin-based proprioceptive feedback. The goal of the task was to perform 5 right and left single-leg extensions at a force perceived to be $10 \mathrm{~kg}$ $(98 \mathrm{~N})$ on the pedal, separated by 3-second intervals [24]. The force was applied to the pedal in the sagittal plane away from the body by performing a knee extension, and only the force registered during this movement phase was recorded.

\section{Procedures}

A pre-test and post-test measurement was adopted in which changes in kinaesthetic differentiation were assessed before and after the 1-month period.

The kinesthesiometer was calibrated before each trial with 1,5 , and $10 \mathrm{~kg}$ loads. The participants were familiarized with the device and the protocol, including information on the force to be applied, the number of repetitions, and the interval between repetitions. All familiarization and experimental trials were performed in the seated position without back support to eliminate the effects of back exteroreceptors. During the familiarization phase, the participants observed a monitor which provided an instantaneous reading of the generated force. No visual feedback on force output was provided during the experimental phase of the test. All testing was performed at the same time of day.

\section{Data analysis}

The level of kinaesthetic differentiation was determined by first averaging the force values of the 5 repetitions. The absolute difference between this mean and each individual repetition was then determined and again averaged. This mean of the sum of differences of the force generated across the 5 repetitions provided a measure of force production accuracy (FPA). This variable was previously determined as a valid measure of kinaesthetic differentiation [27, 28], in which the lower the magnitude, the less variability in force between each repetition, signifying enhanced 
R. Blacha et al., Kinaesthetic sense in seagoing and recreational sailors

kinaesthetic sense [24]. The distribution of the data set was screened for normality and analysed with parametric methods. The Student's $t$-test was used to compare the groups for anthropometric data and age. The pre- and post-test between-group differences in FPA were compared with analysis of variance (ANOVA) for repeated measures and Tukey's post-hoc test. Additionally, the pre- and post-test within-group differences in FPA were compared with the Student's $t$-test. The level of significance was set at $p<0.05$ and data are presented as means \pm standard deviations.

\section{Ethical approval}

The research related to human use has been complied with all the relevant national regulations and institutional policies, has followed the tenets of the Declaration of Helsinki, and has been approved by the Ethics Committee for Research at the University School of Physical Education in Wroclaw.

\section{Informed consent}

Informed consent has been obtained from all individuals included in this study.

\section{Results}

Between-group ANOVA revealed no differences for left knee extension at pre-test ( $p=0.0580, F=3.0395$ ) or at post-test ( $p=0.6149, F=0.4915)$. For right knee extension at pre-test, significant differences were observed ( $p=0.0196, F=4.3032)$ between professional sailors and recreational sailors $(p=0.0183)$, and no between-group differences were found at post-test ( $p=$ $0.1299, F=2.1385$ ).

The Student's $t$-test (within-group) revealed a significant difference between pre- and post-test for the left limb in professional sailors ( $p=0.0006)$; none of the remaining differences achieved statistical significance.
Table 1 presents the pre- and post-test FPA data for all the 3 groups (within-group). FPA increased in professional sailors by $0.70 \%(\Delta: 0.09 \mathrm{~N})$ for the right limb and by $79.12 \%(\Delta: 6.71 \mathrm{~N})$ for the left limb. In the group of recreational sailors, FPA increased by $18.97 \%(\Delta: 1.56 \mathrm{~N})$ for the right limb and by $20.26 \%$ $(\Delta: 1.17 \mathrm{~N})$ for the left limb. Among non-sailors, FPA decreased by $6.97 \%(\Delta: 0.69)$ for the right limb and by $1.42 \%(\Delta: 0.34 \mathrm{~N})$ for the left limb.

\section{Discussion}

Kinaesthetic perception is critical in fluent movement execution, including the precise determination of the force requirements of a movement. Sailing demands the manipulation of many objects and a high degree of force sensation in a given movement is necessary to prevent an uncontrolled situation and maintain safety. One of the manifestations of kinaesthetic differentiation is the force generated in voluntary and consciously perceived movements [10, 12, 25]. It was assumed in the present study that the effects of time spent onboard a seagoing vessel could decrease the level of kinaesthetic differentiation. The findings confirmed this assumption, as evidenced by the reduced accuracy of force repeatability. FPA increased in both professional and recreational sailors, indicating decreased kinaesthetic differentiation, albeit only the reduction in the left lower limb in professional sailors achieved statistical significance $(p=0.0006)$. All subjects were right-handed; hence, in the case of crossed lateralization, their left leg should be more efficient and probably more sensitive to a stimuli. A significant change only in the professional sailors group can be a consequence of greater motor involvement in the activities performed during the shift on the deck of a unit. In contrast with the above findings, FPA decreased among non-sailors, signifying enhanced kinaesthetic differentiation.

Table 1. Pre- and post-test lower limb force production accuracy (FPA)

\begin{tabular}{|c|c|c|c|c|c|c|c|c|c|c|c|c|c|c|c|}
\hline \multirow{2}{*}{$\begin{array}{l}\text { Movement } \\
\text { task }\end{array}$} & \multicolumn{3}{|c|}{ Pre-test } & \multicolumn{3}{|c|}{ Post-test } & \multicolumn{3}{|c|}{ (NS-NS) } & \multicolumn{3}{|c|}{ (PS-PS) } & \multicolumn{3}{|c|}{ (RS-RS) } \\
\hline & NS & PS & RS & ND & PS & $\mathrm{RS}$ & $\Delta$ & $p$ & $t$ & $\Delta$ & $p$ & $t$ & $\Delta$ & $p$ & $t$ \\
\hline $\begin{array}{l}\text { Right knee } \\
\text { extension }\end{array}$ & $\begin{array}{c}9.89 \pm \\
3.90\end{array}$ & $\begin{array}{c}12.80 \pm \\
5.13\end{array}$ & $\begin{array}{c}8.22 \pm \\
3.88\end{array}$ & $\begin{array}{c}9.20 \pm \\
4.71\end{array}$ & $\begin{array}{c}12.89 \pm \\
7.01\end{array}$ & $\begin{array}{c}9.78 \pm \\
4.07\end{array}$ & -0.69 & 0.6528 & 0.4543 & 0.09 & 0.9650 & -0.0441 & 1.56 & 0.3277 & -0.9990 \\
\hline $\begin{array}{l}\text { Left knee } \\
\text { extension }\end{array}$ & $\begin{array}{c}12.97 \pm \\
6.05\end{array}$ & $\begin{array}{c}8.48 \pm \\
4.29\end{array}$ & $\begin{array}{c}12.63 \pm \\
7.37\end{array}$ & $\begin{array}{c}12.78 \pm \\
8.47\end{array}$ & $\begin{array}{c}15.19 \pm \\
6.19\end{array}$ & $\begin{array}{c}14.34 \pm \\
6.44\end{array}$ & -0.34 & 0.9432 & 0.0718 & 6.71 & $0.0006^{*}$ & -3.7713 & 1.17 & 0.5345 & -0.6302 \\
\hline
\end{tabular}

NS - non-sailors, PS - professional sailors, RS - recreational sailors

Data are presented as means \pm standard deviations

Negative $\Delta$ indicates an improvement in FPA

${ }^{*} p<0.05$, significantly different 
The increase in FPA among sailors for both right and left lower limb may be associated with exposure to the pitch, yaw, and roll of the boat and unstable conditions experienced when sailing. The inherent rocking motion has a strong effect on sensory imbalance (particularly vision and balance) and can often result in kinetosis [29]. Conflicting information from the vestibular and oculomotor systems in the central nervous system can induce a number of symptoms, including motor difficulties [30]. Studies have reported that vertical sinusoidal motion such as that experienced on a watergoing craft, particularly at a frequency of $0.2 \mathrm{~Hz}$, has a high nauseogenic potential and causes a number of disturbances [6, 31]. The additional effects of swaying, rolling, and pitching motions can intensify the symptoms of kinetosis, as can wave height, boat size, and hull characteristics [15]. Research suggests that the effects of kinetosis can be reduced by the creation of new motor schemas [16].

Another explanation for the changes observed in the professional and recreational sailors can be the overregulation of muscle tension as a result of spending 1 month on a seagoing vessel. The time spent walking on an unstable surface with excess muscle, tendon, and ligament tension may have modified the pre-existing dryland gait characteristics and postural mechanisms. New compensatory strategies may have been developed to reduce muscle tension so as to enhance balance on a swaying deck, which in effect modified post-sailing dryland neuromuscular function [32, 33]. However, an earlier study on the changes in kinaesthetic differentiation before and after an 85-hour sailing course found no significant differences [8]. Studies in other domains have reported significant improvements in this ability such as after a ski lesson [27] and exercise [28]. Colwin [34], in turn, claimed that professional swimmers with a higher level of kinaesthetic differentiation were able to generate force during a swim stroke more effectively than less experienced swimmers. The cited literature suggests a modulated effect on kinaesthetic differentiation, depending on the type of exercise modality or physical activity.

The present findings must be interpreted with caution. The selection of a 4-second interval between repetitions was not validated nor was this interval evaluated if sufficient in duration to eliminate the effects of between-repetition fatigue. Another factor was the selection of a single-sex population with a wide age range of 21-43 years. Changes in the accuracy of force repeatability were also observed over a relatively short time window, as some sailing trips take several months and testing performed at later time points post-trip may show a return to baseline levels. Despite the fact that the technical and environmental conditions during the cruises were similar, there are no data from the accelerometer, which could prove this fact. In turn, the use of a posturograph would provide additional information and complete the consideration. The statistical test executed in the pre-test setting indicated between-group differences in the ability of kinaesthetic differentiation, proving it crucial to conduct and report. In addition, during sailing, the subjects received online feedback, which is not found in laboratory conditions. However, ecological validity meaning approximate condition to the real world is not necessary to the overall validity of a study. All the indicated limitations excuse the pilot character of this study. The pointed weaknesses should be taken into account in further investigation.

From a practical standpoint, the present study provides insight to the degradation of kinaesthetic differentiation after spending time onboard a seagoing vessel. This may warrant the addition of appropriate kinaesthetic training, although significant research is needed to document the kinaesthetic level in sailingspecific tasks and scenarios. The introduction of the kinaesthetic component in sailing training could help enhance muscle memory of the force or direction required in a given movement [35]. Kinaesthesia is an important factor in many motor skills [36] and reduced kinaesthetic perception can negatively affect motor function [37]. It may be possible that the changes observed in the present study are a temporal dynamic characteristic of this type of physical activity. Kinaesthetic training could counteract these changes, although further research is required on the relationship between kinaesthesia and sailing performance.

\section{Conclusions}

A 1-month sailing intervention reduced lower limb kinaesthetic differentiation as measured by the accuracy of reproducing a pre-specified force in both professional and recreational sailors. This was in contrast with the non-sailors group, in which the accuracy of force reproduction increased. Comparative analysis revealed a significant difference only among professional sailors and for the left lower limb $(p=0.0006)$.

\section{Disclosure statement}

No author has any financial interest or received any financial benefit from this research.

\section{Conflict of interest}

The authors state no conflict of interest. 
R. Blacha et al., Kinaesthetic sense in seagoing and recreational sailors

\section{References}

1. Komorowski AF, Komorowski A. The Polish sea-sailing infrastructure: the current state and development perspectives. Res Yearbook Stud Phys Educ Sport. 2006; 12(2):291-294.

2. Carta MG, Maggiani F, Pilutzu L, Moro MF, Mura G, Cadoni F, et al. Sailing for rehabilitation of patients with severe mental disorders: results of a cross over randomized controlled trial. Clin Pract Epidemiol Mental Health. 2014;10:73-79; doi: 10.2174/17450179014100 10073.

3. Carmont MR. Sailing and yachting. In: Mei-Dan O, Carmont MR (eds.), Adventure and extreme sports injuries. London: Springer; 2013; 203-223.

4. Araújo D, Davids K, Serpa S. An ecological approach to expertise effects in decision-making in a simulated sailing regatta. Psychol Sport Exerc. 2005;6(6):671-692; doi: 10.1016/j.psychsport.2004.12.003.

5. Araújo D, Davids K, Hristovski R. The ecological dynamics of decision making in sport. Psychol Sport Exerc. 2006;7(6):653-676; doi: 10.1016/j.psychsport.2006. 07.002 .

6. Spurway N, Legg S, Hale T. Sailing physiology. J Sports Sci. 2007;25(10):1073-1075; doi: 10.1080/026404106 01165171.

7. Vangelakoudi A, Vogiatzis I, Geladas N. Anaerobic capacity, isometric endurance, and Laser sailing performance. J Sports Sci. 2007;25(10):1095-1100; doi: 10.1080/02640410601165288.

8. Błacha R, Piwowarczyk P. Evaluation of training effectiveness in recreational sailing and its effect on the repeatability of the generated power in the upper limbs [in Polish]. Rozprawy Naukowe AWF Wrocław. 2015; 51:92-105.

9. Lovelace EA, Aikens JE. Vision, kinesthesis, and control of hand movement by young and old adults. Percept Motor Skills. 1990;70(3):1131-1137; doi: 10.2466/pms. 1990.70.3c.1131.

10. Raczek J, Mynarski W, Ljach W. Developing and diagnosing coordination motor skills: a manual for teachers, trainers and students [in Polish]. Katowice: AWF; 2003.

11. Zaton $\mathrm{K}$. The role of verbal information about sensory experience from movement apparatus in the process of swimming economization. In: Kjendlie PL, Stallman RK, Cabri J (eds.), Biomechanics and Medicine in Swimming XI: Proceedings of the $\mathrm{XI}^{\text {th }}$ International Symposium for Biomechanics and Medicine in Swimming. Oslo: Norwegian School of Sport Sciences; 2010; 349-351.

12. Docherty CL, Arnold BL. Force sense deficits in functionally unstable ankles. J Orthop Res. 2008;26(11):14891493; doi: 10.1002/jor.20682.

13. Fernandez RP. The seasickness as marine problem case study. J Marine Sci Appl. 2013;12(1):58-64; doi: 10.1007/s11804-013-1172-y.

14. Lackner JR. Motion sickness: more than nausea and vomiting. Exp Brain Res. 2014;232(8):2493-2510; doi: 10.1007/s00221-014-4008-8.
15. Bos JE. Nuancing the relationship between motion sickness and postural stability. Displays. 2011;32(4): 189-193; doi: 10.1016/j.displa.2010.09.005.

16. Bos JE, Bles W, Groen EL. A theory on visually induced motion sickness. Displays. 2008;29(2):47-57; doi: 10.1016/j.displa.2007.09.002.

17. Kenney WL, Wilmore JH, Costill DL. Physiology of sport and exercise, $5^{\text {th }}$ ed. Champaign: Human Kinetics; 2012.

18. Proske U, Gandevia SC. The proprioceptive senses: their roles in signaling body shape, body position and movement, and muscle force. Physiol Rev. 2012;92(4):16511697; doi: 10.1152/physrev.00048.2011.

19. Cunningham P, Hale T. Physiological responses of elite Laser sailors to 30 minutes of simulated upwind sailing. J Sports Sci. 2007;25(10):1109-1116; doi: 10.1080/02 640410601165668.

20. Castagna O, Brisswalter J. Assessment of energy demand in Laser sailing: influences of exercise duration and performance level. Eur J Appl Physiol. 2007;99(2): 95-101; doi: 10.1007/s00421-006-0336-0.

21. Chattington M, Wilson M, Ashford D, Marple-Horvat DE. Eye-steering coordination in natural driving. Exp Brain Res. 2007;180(1):1-14; doi: 10.1007/s00221-0060839-2.

22. Gale TJ, Walls JT. Development of a sailing dinghy simulator. Simulation. 2000;74(3):167-179; doi: 10.1177/ 003754970007400304.

23. Atkinson G, Reilly T. Circadian variation in sports performance. Sports Med. 1996;21(4):292-312; doi: 10.2165/ 00007256-199621040-00005.

24. Błacha R. Repeatability of isometric muscle tension as a way to measure kinesthetic differentiation ability [in Polish]. Wrocław: AWF; 2013.

25. Mustafa K, Furmanek MP, Knapik A, Bacik B, Juras G. The impact of the Swedish massage on the kinesthetic differentiation in healthy individuals. Int J Ther Massage Bodywork. 2015;8(1):2-11; doi: 10.3822/ijtmb. v8i1.252.

26. Zaton M, Błacha R. The method of measuring the pressure of human limbs and the device for measuring the pressure of human limbs [in Polish]. Biuletyn Urzędu Patentowego. 2008;16:4.

27. Zatoń M, Zatoń K, Zygadło A. Changes in kinaesthetic differentiation capacity in the ski learning process [in Polish]. Antropomotoryka. 2008;18(44):37-47.

28. Zatoń M, Błacha R, Jastrzębska A, Słonina K. Repeatability of pressure force during elbow flexion and extension before and after exercise. Hum Mov. 2009;10(2): 137-143; doi: 10.2478/v10038-009-0010-6.

29. Huppert D, Benson J, Brandt T. A historical view of motion sickness - a plague at sea and on land, also with military impact. Front Neurol. 2017;8:114; doi: 10.3389/ fneur.2017.00114.

30. Murdin L, Chamberlain F, Cheema S, Arshad Q, Gresty MA, Golding JF, et al. Motion sickness in migraine and vestibular disorders. J Neurol Neurosurg Psychi- 
atry. 2015;86(5):585-587; doi: 10.1136/jnnp-2014308331.

31. Wertheim AH, Bos JE, Bles W. Contributions of roll and pitch to sea sickness. Brain Res Bull. 1998;47(5):517524; doi: 10.1016/S0361-9230(98)00098-7.

32. Riccio GE, Stoffregen TA. An ecological theory of motion sickness and postural instability. Ecol Psychol. 1991;3(3):195-240; doi: 10.1207/s15326969eco0303_2.

33. Stoffregen TA, Smart LJ. Postural instability precedes motion sickness. Brain Res Bull. 1998;47(5):437-448; doi: 10.1016/S0361-9230(98)00102-6.

34. Colwin CM. Breakthrough swimming. Champaign: Human Kinetics; 2002.

35. Pinzon D, Vega R, Sanchez YP, Zheng B. Skill learning from kinesthetic feedback. Am J Surg. 2017;214(4): 721-725; doi: 10.1016/j.amjsurg.2016.10.018.

36. Lynch MR, Raymer ME, Elvery JH, Walsh AL, Burns YR. The development of hand position sense. New Zealand J Physiother. 1992;20:15-20.

37. Matheson LN, Kaskutas VK, Mada D. Development and construct validation of the Hand Function Sort. J Occup Rehabil. 2001;11(2):75-86; doi: 10.1023/A: 1016651201397. 